\title{
Some Properties of a Mutant Strain of Escherichia coli which Requires Lysine and Methionine or Lipoic Acid for Growth
}

\author{
By AILSA B. VISE* AND JUNE LASCELLES \\ Microbiology Unit, Biochemistry Department, University of Oxford
}

(Accepted for publication 14 February 1967)

SUMMARY

\begin{abstract}
The requirement of a mutant strain of Escherichia coli for lysine+ methionine was due to its inability to make lipoic acid. Aerobic growth of the mutant in minimal medium + lipoic acid was equal to that of the wildtype organism. The factor was replaceable by acetate + succinate. When grown without lipoic acid, suspensions of this organism did not oxidize pyruvate but did so upon addition of the factor; they also accumulated pyruvate from glucose. Extracts from deficient organisms did not oxidize $\alpha$-ketoglutarate with 3-acetyl-NAD as acceptor. The growth requirements were only exhibited aerobically when provision of acetate + succinate required the operation of the lipoic-dependent pyruvate and $\alpha$-ketoglutarate oxidase systems, respectively. Anaerobically, these metabolites were formed by lipoic-independent mechanisms, such as fumarate reductase which is repressed by oxygen.
\end{abstract}

\section{INTRODUCTION}

Mutant strains of Escherichia coli have been described which respond to mixtures of methionine and lysine (Back \& Westaway, 1962; Taylor \& Thoman, 1964). One of these strains has been examined in the present work; it responded to lipoic acid in place of lysine + methionine and it appeared that the primary lesion was an inability to synthesize lipoic acid, which led to secondary effects on the metabolism of the organism. Lipoic acid is a growth factor for several micro-organisms and its function has been established as an electron acceptor in the oxidative decarboxylation of pyruvate and $\alpha$-ketoglutarate (Reed, 1960). It has, therefore, an important role in the metabolism of substrates by the tricarboxylic acid cycle. In the present work the mutant was used to study the effect of deficiency of lipoic acid on the growth requirements of the organism under aerobic and anaerobic conditions, and to examine at the enzymic level the reasons for the observed growth responses.

\section{METHODS}

Organisms. Escherichia coli strain 15 was derived from E. coli strain 518 (Back \& Westaway, 1962) and both strains were maintained by monthly subculture on Oxoid nutrient agar slopes, incubated for $18 \mathrm{hr}$ at $37^{\circ}$ and stored at $4^{\circ}$.

Growth tests. Minimal medium C containing inorganic salts with $0 \cdot 2 \%(\mathrm{w} / \mathrm{v})$ glucose was the basal medium (Roberts et al. 1957). The inoculum (equivalent $0.25 \mu \mathrm{g}$.

* Present address: Sir William Dunn School of Pathology, University of Oxford. 
dry-wt organism/ml.) was prepared from washed organisms grown overnight on nutrient agar slopes. Anaerobic incubation was in completely filled tubes sealed with a rubber bung; aerobic cultures were grown in $5 \mathrm{ml}$. volumes in $15 \mathrm{~mm}$. diam. tubes shaken on a reciprocating shaker at 120 oscillations/min. Growth was measured after incubation for $24 \mathrm{hr}$ at $37^{\circ}$ with an EEL colorimeter (Evans Electroselenium Ltd., Harlow, Essex) and is recorded as equiv. mg. dry-wt organism/ml. (instrument reading $10=0.33 \mathrm{mg} . / \mathrm{ml}$.).

Experiments with suspensions of organisms. Organisms were grown at $37^{\circ}$ in medium $\mathrm{C}$, supplemented as required. The inoculum was derived from nutrient agar slopes and was equivalent to about $2 \mu \mathrm{g}$. dry-wt organism $/ \mathrm{ml}$. Aerobic cultures were in $300 \mathrm{ml}$. volumes in 21 . flasks, incubated with shaking at 300 oscillations/min.; anaerobic growth was in completely filled flasks. The cultures were harvested by centrifugation after incubation for $10 \mathrm{hr}$ while still in the logarithmic phase of growth. The organisms were washed in 0.04 M-phosphate buffer ( $\mathrm{pH} \mathrm{7.0)}$ ) and resuspended in the same buffer to a concentration equiv. 10-15 mg. dry-wt. organism $/ \mathrm{ml}$.

Respiratory activity was determined manometrically at $37^{\circ}$. Formation of products from glucose utilization was determined with organisms incubated aerobically or anaerobically in reaction mixtures containing per ml.; organisms, equiv. $20 \mathrm{mg}$. drywt; potassium phosphate buffer ( $\mathrm{pH} 7.0$ ), $100 \mu$ moles; glucose, $20 \mu$ moles. Aerobic incubation was in $4 \mathrm{ml}$. volumes in $50 \mathrm{ml}$. flasks shaken at 300 oscillations/min. and anaerobic incubation was in tubes under an atmosphere of nitrogen. After incubation for $3 \mathrm{hr}$ at $37^{\circ}$ the suspensions were centrifuged at $0^{\circ}$ and the supernatant fluids analysed for products.

Analytical methods. Glucose was determined by the method of Huggett \& Nixon (1957). Pyruvate was estimated as the 2,4-dinitrophenylhydrazone (Friedemann \& Haugen, 1943). Acetate was measured by the method of Rose (1955) which involves its conversion to acetyl phosphate with acetokinase and measurement of the acetyl phosphate by the hydroxamate method of Lipmann \& Tuttle (1945). A crude extract of aerobically grown Escherichia coli 518 was used as the source of acetokinase.

Preparation of cell-free extracts. Suspensions of organisms (equiv. $20 \mathrm{mg}$. dry-wt/ ml. in 0.04 M-phosphate buffer, $\mathrm{pH} \mathrm{7.0)}$ were disrupted by ultrasonic treatment for 4 min. with a Mullard E 7590 B generator operating at $3.5 \mathrm{~A}$. and producing $25 \mathrm{kc}$./ sec. The preparations were centrifuged at $18,000 \mathrm{~g}$ for $15 \mathrm{~min}$. at $4^{\circ}$ and the supernatant fluids used for the determination of enzymic activities. Protein was measured spectrophotometrically (Warburg \& Christian, 1941).

Assays of enzyme activity. $\alpha$-Ketoglutarate dehydrogenase was measured spectrophotometrically by the method of Amarasingham \& Davis (1965), in which 3-acetylNAD is the electron acceptor; it was also assayed with ferricyanide as acceptor in the system of Hager \& Kornberg (1961), measurement being made at $420 \mathrm{~m} \mu$. Lipoic acid dehydrogenase was measured by the method of Hager \& Gunsalus (1953), except that disappearance of sulphydryl groups was estimated by the procedure of Ellman (1959). Reduced lipoic acid, required for this assay, was prepared by the method of Wagner et al. (1956). Fumarate reductase was assayed anaerobically by following the rate of oxidation of reduced benzylviologen in the presence of fumarate; measurement was made with the EEL colorimeter, using a 625 filter (Wyn-Jones \& Lascelles, 1967).

Special chemicals. DL-lipoic acid (L. Light and Co. Ltd., Colnbrook, Bucks., Eng1and) was used. 3-Acetyl-NAD was from Calbiochem (California, U.S.A.); 5,5'- 
dithio-bis(2-nitrobenzoic acid), for the determination of sulphydryl groups, was from the Aldrich Chemical Co. Inc. (Milwaukee, Wisconsin, U.S.A.); benzylviologen was from British Drug Houses Ltd.

\section{RESULTS}

\section{Growth requirements under aerobic and anaerobic conditions}

Under aerobic conditions, growth of the mutant strain 15 of Escherichia coli was dependent on lipoic acid, and with this supplement it grew as well as the parent organism in the unsupplemented medium (Table 1). Lipoic acid was replaced by a mixture of acetate + succinate, though neither substance alone was effective and growth did not attain the degree given with lipoic acid. The low concentration of lipoic acid required for maximum growth (about $5 \mathrm{~m} \mu \mathrm{M}$ ) was of the same order as that required by other exacting micro-organisms. The requirement of acetate + succinate was higher by several orders of magnitude, which was to be expected if lipoic acid functioned catalytically in their synthesis. Anaerobically, the mutant grew on the unsupplemented minimal medium to the same extent as the parent, and the addition of lipoic acid or of acetate + succinate had no effect (Table 1).

Table 1. Growth responses of Escherichia coli strains 15 and 518

Cultures were grown as described in the Methods in medium C supplemented as shown.

$\begin{array}{cccccc}\text { Strain } & \begin{array}{c}\text { Acetate } \\ (\mathrm{mM})\end{array} & \begin{array}{c}\text { Succinate } \\ (\mathrm{mM})\end{array} & \begin{array}{c}\text { DL-lipoic acid } \\ (\mathrm{m} \mu \mathrm{M})\end{array} & \overbrace{\text { Aerobic }}^{\begin{array}{c}\text { Growth in } 24 \mathrm{hr} \text { (equiv. mg. } \\ \text { dry-wt organism/ml.) }\end{array}} & \text { Anaerobic } \\ 518 & - & - & - & 0.71 & 0.34 \\ 15 & - & - & - & 0 & 0.31 \\ & 1 & - & - & 0 & 0.26 \\ & -1 & 1 & - & 0 & 0.28 \\ & - & - & 10 & 0.35 & 0.31 \\ & - & - & & 0.71 & 0.31\end{array}$

Utilization of glucose and pyruvate by suspensions of organisms

The difference in behaviour under aerobic and anaerobic conditions suggested that the mutant could make acetate + succinate anaerobically by lipoic-independent mechanisms, whereas aerobically these metabolites were provided by the lipoicdependent oxidation of pyruvate and $\alpha$-ketoglutarate. This was partially confirmed by experiments with suspensions of the mutant and parent strains grown with and without lipoic acid.

Suspensions of the mutant grown aerobically without lipoic acid (with acetate + succinate present) did not oxidize pyruvate but did so upon addition of the factor (Fig. 1). Suspensions of such deficient organisms accumulated pyruvate when incubated aerobically with glucose, in contrast to organisms grown with lipoic acid which behaved like the parent strain (Table 2). Surprisingly, acetate was also found as a product of glucose utilization by lipoic-acid-deficient organisms. This acetate might have been formed via the pyruvate oxidase system which is induced by pyruvate and which is formed in the later stages of growth of Escherichia coli (Gounaris \& Hager, 1961). The reaction does not appear to be quantitatively significant for the growing 


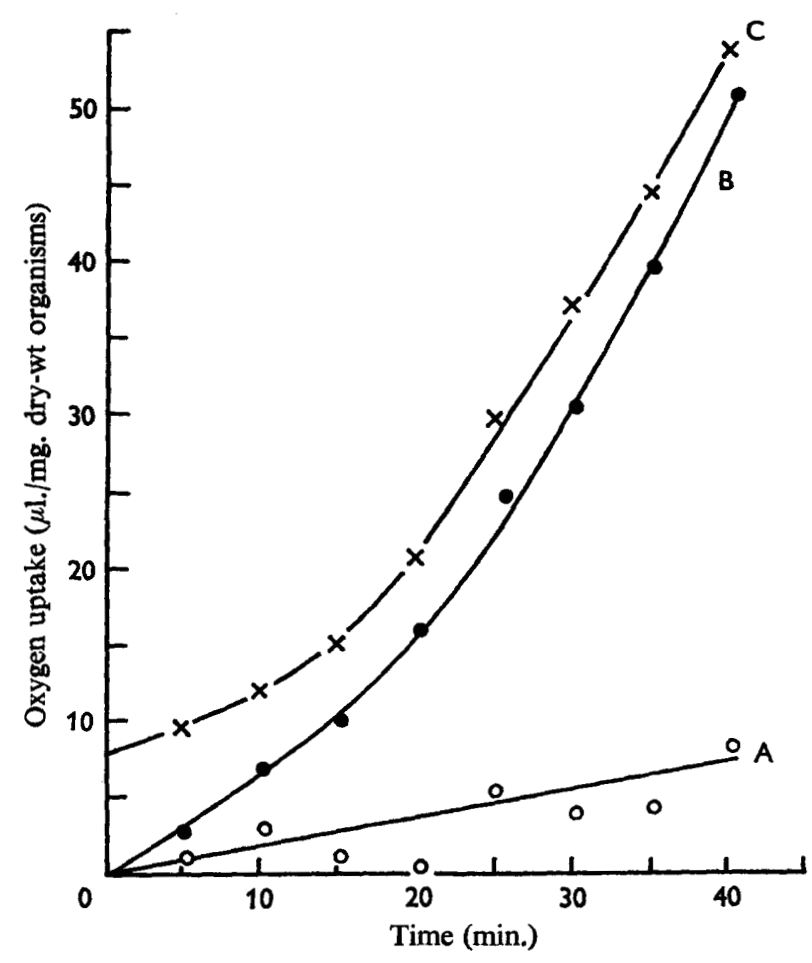

Fig. 1. Oxidation of pyruvate by suspension of Escherichia coli strain 15. Each manometer vessel contained in $2.5 \mathrm{ml}$.: organisms (equiv. $10 \mathrm{mg}$. dry-wt) suspended in $50 \mathrm{~mm}$-phosphate buffer (pH 7.0) with sodium pyruvate ( $20 \mu$ moles) added at zero time from the side arm; lipoic acid $(1 \mu$ mole) was present in $\mathrm{B}$. The centre well contained $5 \mathrm{~N}-\mathrm{NaOH}$. Incubation was at $37^{\circ}$ in air. The endogenous respiration (not more than $12 \mu \mathrm{l} . / \mathrm{mg}$. dry-wt organism/hr) has been subtracted. Curves $\mathrm{A}$ and $\mathrm{B}$ contained lipoic-deficient organisms, grown with mMacetate + succinate; curve C contained organisms grown with $10 \mathrm{~m} \mu \mathrm{M}$-lipoic acid.

Table 2. Formation of acetate and pyruvate from glucose by suspensions of Escherichia coli strains 15 and 518

Organisms were grown in the basal medium supplemented as indicated, and the washed suspensions incubated aerobically or anaerobically in $4.0 \mathrm{ml}$. mixture containing: organisms, equiv. $80 \mathrm{mg}$. dry-wt; potassium phosphate buffer (pH 7.0), $400 \mu$ moles; glucose, $80 \mu$ moles. Incubation was for $3 \mathrm{hr}$, by which time the glucose was completely utilized. After removal of the organisms by centrifugation acetate and pyruvate were determined in the supernatant fluids (see Methods).

Strain Growth conditions

15 Aerobic with $10 \mathrm{~m} \mu_{\mathrm{M}}$-lipoic acid Aerobic with $\mathrm{mm}$ acetate + succinate Anaerobic without supplement

518 Aerobic without supplement Anaerobic without supplement

\begin{tabular}{|c|c|}
\hline \multicolumn{2}{|c|}{ Products found } \\
\hline Aerobically & Anaerobically \\
\hline
\end{tabular}
( $\mu$ moles/ml.)

$\begin{array}{rlrl}2.0 & 1.6 & 11 & 0.7 \\ 7 & 8 & 14 & 0.7 \\ 14 & 0.4 & 8 & 1.3 \\ 3 & 0.6 & 13 & 0.5 \\ 15 & 2.2 & 13 & 0.4\end{array}$


organism since the mutant requires exogenous acetate when grown aerobically without lipoic acid.

Under anaerobic conditions, suspensions of the lipoic acid deficient mutant behaved like the parent strain; only small amounts of pyruvate were detected and there was considerable accumulation of acetate (Table 2). These observations confirmed the existence of a lipoic-independent mechanism for acetate formation, which operated under anaerobic conditions.

\section{Enzymic activities}

Lipoic dehydrogenase. The activity of this enzyme was examined in extracts of the mutant and parent strain grown under various conditions (Table 3). The enzyme was present in the mutant grown either with or without lipoic acid and was, indeed, significantly higher in organisms grown aerobically with acetate and succinate in place of the factor. The level of activity in both parent and mutant organisms grown anaerobically was about one third of that found in aerobic organisms.

Table 3. Enzymic activities in extracts of Escherichia coli strains 15 and 518

Organisms were grown in the salts medium supplemented as shown. Activities were determined in extracts of the organisms as described in the Methods.

\begin{tabular}{|c|c|c|c|c|c|}
\hline \multirow{2}{*}{$\begin{array}{c}\text { Strain } \\
15\end{array}$} & \multirow{2}{*}{$\begin{array}{l}\text { Growth conditions } \\
\text { Aerobic with } 10 \mathrm{~m} \mu \mathrm{M}-\text { lipoic acid } \\
\text { Aerobic with } \mathrm{mm} \text { acetate+ succinate } \\
\text { Anaerobic without supplement }\end{array}$} & \multirow{2}{*}{$\begin{array}{c}\begin{array}{c}\text { Lipoic } \\
\text { dehydro- } \\
\text { genase }\end{array} \\
\text { ( } \mu \text { moles st } \\
1.4 \\
2.4 \\
0.4\end{array}$} & $\overbrace{\begin{array}{r}\alpha-\mathrm{Ke} \\
\text { dehy }\end{array}}^{\text {NAD* }}$ & Ferricyanic & $\begin{array}{l}\text { Fumarate } \\
\text { r/mg. protein) }\end{array}$ \\
\hline & & & $\begin{array}{l}0.07 \\
0 \\
0\end{array}$ & $\begin{array}{l}1 \cdot 7 \\
1 \cdot 26 \\
0\end{array}$ & $\begin{array}{l}0.85 \\
0.85 \\
7.8\end{array}$ \\
\hline 518 & $\begin{array}{l}\text { Aerobic without supplement } \\
\text { Anaerobic without supplement }\end{array}$ & $\begin{array}{l}1.4 \\
0.6\end{array}$ & $\begin{array}{l}0.06 \\
0\end{array}$ & $\begin{array}{l}1 \cdot 26 \\
0\end{array}$ & $\begin{array}{l}0.45 \\
4.3\end{array}$ \\
\hline
\end{tabular}

Enzymes concerned in succinate formation. The dependence of the mutant upon succinate for aerobic growth without lipoic acid could be attributed to its inability to form succinate from $\alpha$-ketoglutarate via the $\alpha$-ketoglutarate oxidase system. Extracts of the mutant grown aerobically without lipoic acid contained no detectable $\alpha$-ketoglutarate dehydrogenase activity with 3-acetyl-NAD as electron acceptor, but the activity was found with ferricyanide, which bypasses lipoic acid as electron acceptor. Preparations from the mutant grown aerobically with lipoic acid had both activities at degrees similar to that found in the parent (Table 3). $\alpha$-Ketoglutarate dehydrogenase with 3-acetyl-NAD or ferricyanide as acceptor was detectable only in organisms grown aerobically; this applied to both parent and mutant strains and confirmed recent observations of Amarasingham \& Davis (1965).

The ability of the mutant to grow anaerobically without added succinate could be attributed to the synthesis of succinate by fumarate reductase. This enzyme catalyses fumarate reduction more rapidly than succinate oxidation, whereas succinic dehydrogenase favours the formation of fumarate from succinate (Hirsch, Rasminsky, Davis \& Lin, 1963). Fumarate reductase was high in mutant and parent organisms grown anaerobically (Table 3). In both strains it was repressed by oxygen, and in the case of the mutant the degree of activity was low in organisms grown with or without lipoic 
acid. Repression of this enzyme by oxygen accounts for the dependence of the mutant on added succinate when the normal mechanism for its aerobic formation from $\alpha$-ketoglutarate is prevented by deficiency of lipoic acid.

\section{DISCUSSION}

The mutant strain 15 of Escherichia coli is apparently blocked at a stage in the synthesis of lipoic acid; there is no knowledge of this biosynthetic pathway. The consequences of lipoic acid deficiency only become evident when the cultures are grown aerobically and are dependent upon the operation of the tricarboxylic acid cycle for the biosynthesis of intermediates. Under these conditions the organism apparently forms acetate + succinate predominantly by the lipoic-mediated pyruvate and $\alpha$ ketoglutarate oxidase complexes. Other enzymic mechanisms which provide these metabolites by lipoic-independent steps are repressed or inhibited by oxygen, whereas they can function anaerobically. Consequently, the mutant grows anaerobically without supplementation.

Acetate can be formed anaerobically by Escherichia coli by the phosphoroclastic reaction, which is not detectable in organisms grown aerobically (Henning, 1963). The pyruvate-induced pyruvate oxidase described by Gounaris \& Hager (1961) does not apparently provide sufficient acetate to support growth of the mutant. The alternative anaerobic mechanism for succinate formation is by the fumarate reductase enzyme, which is repressed by oxygen in both mutant and parent strain. Repression of this enzyme by aerobiosis was previously found by Hirsch et al. (1963).

The original observations of the response of the Escherichia coli mutant 15 to lysine + methionine may be partly explained as follows. Succinylation reactions occur in the biosynthesis of both amino acids (Davis et al. 1959; Rowbury \& Woods, 1964) and their addition to the medium would therefore spare the requirement for succinate. However, the fact that acetate is no longer necessary for growth when these amino acids are present is more difficult to understand. Possibly, lipoic-independent reactions for acetate formation, such as the system described by Gounaris \& Hager, (1961) may provide sufficient amounts of acetate when other growth requirements have been met. A similar pattern of growth responses has been observed with a mutant strain of $E$. coli which requires 4-hydroxybenzoic acid, a precursor of quinones (Wyn-Jones \& Lascelles, 1967). Aerobic growth occurs without the factor in the presence of methionine +lysine or succinate; under anaerobic conditions, however, the organism grows without supplementation. Thus, with both mutant strains, a deficiency in the aerobic electron transport chain results in an impairment in the tricarboxylic acid cycle as a source of intermediates.

A. B. V. held a Walter and Eliza Hall Travelling Scholarship during this work.

\section{REFERENCES}

Amarasingham, C. R. \& Davis, B. D. (1965). Regulation of $\alpha$-ketoglutarate dehydrogenase formation in Escherichia coli. J. biol. Chem. 240, 3664.

BACK, K. J. C. \& WestaWAY, E. G. (1962). Studies on a mutant strain of Escherichia coli which requires both methionine and lysine for growth. J. gen. Microbiol. 27, 41. 
Davis, B. D., Kornberg, H. L., Nagler, A., Mrller, P. \& Mingioli, E. (1959). Formation and functions of succinate in Escherichia coli. Fedn Proc. Fedn Am. Socs. exp. Biol. 18, 211.

Ellman, G. L. (1959). Tissue sulfhydryl groups. Archs Biochem. Biophys. 82, 70.

Friedranan,, T. E. \& Haugen, G. E. (1943). Pyruvic acid. II. The determination of keto acids in blood and urine. J. biol. Chem. $147,415$.

Gounaris, A. D. \& HAGER, L. P. (1961). A resolution of the Escherichia coli pyruvate dehydrogenase complex. J. biol. Chem. 236, 1013.

HAGER, L. P. \& GunSALUS, I. C. (1953). Lipoic acid dehydrogenase: the function of $E$. coli fraction B. J. Am. chem. Soc. 75, 5767.

HAGER, L. P. \& KorNBerg, H. L. (1961). On the mechanism of $\alpha$-oxoglutarate oxidation in Escherichia coli. Biochem. J. 78, 194.

HenNING, U. (1963). Ein Regulationsmechanismus beim Abbau der Brenztraubensäure durch Escherichia coli. Biochem. Z. 337, 490.

Hirsch, C. A., Rasminsky, M., Davis, B. D. \& Lin, E. C. C. (1963). A fumarate reductase in Escherichia coli distinct from succinate dehydrogenase. J. biol. Chem. $238,3770$.

Hugget, A. ST. G. \& Nixon, D. A. (1957). Use of glucose oxidase, peroxidase. and $o$-dianisidine in determination of blood and urinary glucose. Lancet ii, 368.

LipMANN, F. \& TUTTLE, L. C. (1945). A specific micro method for the determination of acyl phosphates. J. biol. Chem. 159, 21.

ReED, L. J. (1960). Lipoic Acid. In The Enzymes, 2nd ed. Ed. by P. D. Boyer, H. Lardy and K. Myrbäck. Vol. 3, p. 195. New York: Academic Press Inc.

Roberts, R. B., Abelson, P. H., Cowie, D. B., Bolton, E. T. \& BrtTten, R. J. (1957). Studies of biosynthesis in Escherichia coli. Publs Carnegie Instn, no. 607.

Rose, I. A. (1955). Acetate kinase of bacteria. Meth. Enzymol. 1, 591.

ROWBURY, R. J. \& Woods, D. D. (1964). $O$-succinylhomoserine as an intermediate in the synthesis of cystathionine by Escherichia coli. J. gen. Microbiol. 36, 341.

TAYlOR, A. L. \& Thoman, M. S. (1964). The genetic map of Escherichia coli K-12. Genetics 50, 659.

Wagner, A. F., Walton, E., Boxer, G. E., Pruss, M. P., Holly, F. W. \& Folkers, K. (1956). Properties and derivatives of $\alpha$-lipoic acid. J. Am. chem. Soc. 78, 5079.

WARBURG, O. \& Christian, W. (1941). Isolierung und Krystallisation des Garungsferments Enolase. Biochem. Z. 310, 384.

Wyn-Jones, R. G. \& LASCELles, J. (1967). The relationship of 4-hydroxybenzoic acid to lysine and methionine formation in Escherichia coli. Biochem. J. 103, 709. 